\title{
Pressor Unit
}

National Cancer Institute

\section{Source}

National Cancer Institute. Pressor Unit. NCI Thesaurus. Code C48532.

The activity of a pressor agent expressed as one pressor unit being equal to the activity of 0.5 milligram of the USP Standard Powdered Pituitary U.S.P., a USP posterior pituitary reference standard. 